\title{
Assessing Efficiency and Innovation in the 3PL Industry: an Empirical Analysis
}

\author{
Abstract - The Third Party Logistics (3PL) industry is facing both important growth rates and \\ increasing competitive pressure. 3PL providers are required to continuously sustain a more \\ and more competitive cost structure (i.e. efficiency) and develop capabilities to improve their \\ services (i.e. innovation), as such, the evaluation of these key success factors is considered a \\ key issue. This paper develops a quantitative analysis of 71 Italian 3PL providers by using \\ Data Envelopment Analysis to jointly assess efficiency and innovation. Furthermore, through \\ a case study research, it corroborates the quantitative results by investigating the strategies of \\ best-in-class companies. Results allowed identifying 13 3PL providers as efficiency leaders, \\ and 6 as leaders from both efficiency and innovation side. Their input composition indicates a \\ diversification of the business models. A breakdown of the analysis by size and industry \\ focus, along with empirical evidence on the strategies enhancing efficiency and innovation, \\ are also provided.
}

Keywords - 3PL industry; Data Envelopment Analysis; Malmquist index; Case study; Innovation; Efficiency. 


\section{Introduction}

Although logistics outsourcing is a phenomenon with important growth rates for more than a decade, the Third Party Logistics (3PL) industry is facing increasing competitive pressure because of a combination of factors. The annual study conducted by Langley and Capgemini (2015) indicates that, despite the overall market (more than 700 billion US \$) has increased by $30 \%$ from 2010, the annual growth rates are moderating significantly over time $(+13.7 \%$ between 2010 and 2011, +9.9\% between 2011 and 2012, and $+2.7 \%$ between 2012 and 2013), contributing to enhance the already high competitive pressure of the 3PL industry, established first of all by thin profit margins (Min, DeMond, and Joo 2013). Additionally, as Vickery et al. (2004) suggest, the competitive context of 3PL providers has been always characterised by a high level of complexity in terms of task difficulty and variability (e.g. multiple shipments from multiple locations to multiple destinations within multiple periods) and also in terms of uncertainty and interdependence (often involving communication and coordination among multiple supply chain parties). Within this challenging environment, 3PL providers have also to face the ever-changing shippers' needs offering more and more sophisticated and better value-added logistics services to complement their operations, and meet customer service requirements (e.g. Yeung et al. 2006; Large, Kramer, and Hartmann 2011).

To compete successfully in this environment, 3PL providers must be able to offer the service level agreed with shippers at the minimum cost, dealing with these complexities efficiently in order to sustain a competitive cost structure (e.g. Makukha and Gray 2004; Lieb and Bentz 2005; Min, DeMond, and Joo 2013), but also they must develop skills, competencies, and more valueadded activities (e.g. Yeung et al. 2006; Rajesh et al. 2011; Selviaridis and Norman 2015). Maintaining a competitive cost structure by offering only basic services may be no longer suffice. Summing up, new set of skills required for 3PL providers are arising, above all the capability of proposing innovative solutions and offer more complex and shipper-tailored services (e.g. Yeung et 
al. 2006; Large, Kramer, and Hartmann 2011). These efforts in terms of innovations allow 3PL providers to increase shipper satisfaction, establish long-term relationships and maintain competitiveness in the market. More in detail, as the paper of Wallenburg (2009) well specified, innovations by 3PL providers can be divided into 'pure internal' and 'shipper-related' innovations. The first type (i.e. pure internal innovations) refers to innovations that do not affect shippers directly, rather they aim to increase the 3PL provider's operational efficiency. The second type (i.e. shipper-related innovations) concerns innovations that are perceived by shippers as their direct impact on them. This impact may refer to cost reductions and performance improvements for the shipper.

The importance of both maintaining a competitive cost structure and offering innovative solutions for the competitiveness in the 3PL industry is well-recognised by the academic literature. Specifically, the topic of efficiency and innovation in the 3PL industry has been studied within the analysis of the 3PL providers' business models through case study or survey research, according to different perspectives, namely: 3PL providers competences (e.g. Skjoett-Larsen 2000; Bolumole 2003), types of services (e.g. Hertz and Alfredsson 2003; Lai, Cheng, and Yeung 2004; Soinio, Tanskanen, and Finne 2012) and strategies of value creation for shippers (e.g. Berglund et al. 1999; Hertz and Alfredsson 2003; Lai, Cheng, and Yeung 2004; Carbone and Stone 2005; Wallenburg 2009; Prockl, Pflaum, and Kotzab 2012). For instance, according to the third perspective, 3PL providers can focus on operational efficiency by achieving economies of scale or sharing resources between shippers (i.e. efficiency) and can develop capabilities to design logistics solutions to improve shippers' supply chain (i.e. innovation) (e.g. Berglund et al. 1999, Lai, Cheng, and Yeung 2004).

In this arena, the quantitative evaluation of operational efficiency and innovation is considered a key aspect for the understanding of the 3PL industry (e.g. Selviaridis and Spring 2007; 
Asthana 2013). However only few papers focus on the quantitative measurement of these key aspects and, in case, they analyse them separately each other.

The few papers that focussed on the identification and the assessment of the operational efficiency frontier of the 3PL industry proposed non-parametric models such as Data Envelopment Analysis (DEA). Even if in these contributions DEA has been yet successfully adopted for measuring the efficiency, such contributions have analysed only small samples of 3PL providers e.g. Zhou et al. (2008) applied DEA focussing on 10 leading 3PL providers in China; Min and Joo (2009) and Min, DeMond, and Joo (2013) respectively on 12 and 24 leading 3PL providers in North America.

With reference to the quantitative assessment of 3PL providers' innovation, most of the papers used survey as methodology for collecting data about input and output of the innovative process (e.g. Sirilli and Evangelista 1998; Yeung et al. 2006; Wallenburg et al. 2010).

Moreover, the quantitative evaluation of efficiency and innovation have been up to date studied independently from the 3PL providers' business models, so the link of efficiency and innovation of 3PL providers with the strategies adopted to pursue them has not been fully explored. This lack has often led, on one hand, to theoretical frameworks not well supported from empirical data or, on the other hand, to analysis that may not help effectively 3PL providers when setting their business model.

Attempts on the quantitative evaluation of both efficiency and innovation can be found in the extant literature considering other industries. For instance, different contributions have extended DEA to mixed-period DEA models in order to estimate the total productivity change through Malmquist Index (MI) (e.g. Odeck 2008 - in the public transport sector; Pires and Fernandes 2012 - in the airlines sector), and a number of authors have also decomposed this productivity index in its efficiency and technological change terms to isolate the 'innovation' component and identify innovative companies (e.g. Miguéis et al. 2011 in the electricity distribution sector). Even if such 
models are well-recognised, at the best of our knowledge the only attempt to use them in the 3PL industry has been recently performed by Wong, Soh, and Goh (2015), using a panel of Malaysian 3PL providers.

Based on this premise, this paper intends to address the gaps identified by (i) analysing jointly efficiency and innovation in the 3PL industry using a quantitative approach and considering a large sample (i.e. 71 companies), and (ii) providing empirical-based evidence on the link of the quantitative evaluation with the 3PL providers' strategies to pursue of efficiency and innovation.

The reminder of the paper is organised as follow. The next section reports the methodology adopted. Subsequently, the main results about the quantitative evaluation of efficiency and innovation are presented in Section 3, while the case study results are summarised in Section 4. In Section 5, conclusions are drawn and suggestions for future research are identified.

\section{Research Methodology}

The above-mentioned aims of the paper can be disentangled in four research objectives:

- To quantitatively evaluate the efficiency of 3PL providers, considering a period of four years and taking into account the impact of economies of scale;

- To quantitatively evaluate the innovation of 3PL providers by identifying the companies that have been able to lead the industry towards more productive levels over time;

- To identify the best-in-class companies in terms of both efficiency and innovation through a cross-analysis of the previous results;

- To corroborate and link the quantitative results with the 3PL providers' strategies by exploring the strategies through which best-in-class companies have been able to reach high scores of efficiency and innovation.

To answer to these research objectives a mixed methods strategy combining both quantitative and 
qualitative research were adopted.

The first step entailed a thorough review of the extant literature to explore the main benchmarking techniques in the field of efficiency and productivity analysis. Benchmarking techniques are defined as a set of quantitative methods that aim at assessing the relative performance of Decision-Making Units (DMUs, e.g. firms or single plants). Frontier estimation is one of the most frequently used benchmarking techniques and is based on the idea that DMUs can be distinguished according to their distance from a production/cost optimal frontier, which in turn determines the relative efficiency scores. Such technique can be further divided into two main categories: parametric or non-parametric methods. Compared to the former, non-parametric methods do not need to make any assumption about the form of the production/cost frontier but are more sensitive to sample size and outliers, and do not take into account random statistical noise.

Given the difficulty to make any assumption about the functional form, DEA models were identified as the most appropriate quantitative method to address the first three research objectives. DEA is a set of non-parametric models that have been applied for more than three decades and have proven useful in a number of sectors and applications, including the 3PL industry (e.g. cellular manufacturing - Talluri, Hug, and Pinney 1997; banks - Thanassoulis 1999; container ports Cullinane and Wang 2006; hospitals - O’Neill et al. 2008; 3PL industry - Min, DeMond, and Joo 2013; urban mass transit systems - Min, Ahn, and Lambert 2015). The original idea behind DEA is to provide a methodology whereby, within a set of comparable DMUs, those exhibiting best practice could be identified and would form an efficient frontier. Furthermore, the methodology enables to measure the efficiency level of non-frontier units and identify benchmarks against which such inefficient units can be compared (Cook and Seiford 2009). DEA models rely on linear programming that measures the efficiency of the sample based on the input-to-output ratio. The efficient frontier is a hyperplane (in the case of more than two variables) composed of the DMUs that have the best input-to-output ratio (Pires and Fernandes 2012). 
As mentioned earlier, a number of contributions have extended DEA to mixed-period DEA models in order to estimate the total productivity change, and therefore identify innovative companies, through Malmquist Index. First introduced by Sten Malmquist (1953) in the context of consumer theory, it was adapted to productivity measurement by Caves, Christensen, and Diewart (1982) and further enhanced by Färe, Grosskopf, and Lovell (1994) and nowadays it is one of the most frequently used techniques to measure productivity changes over time.

Data Envelopment Analysis (DEA) and DEA-based Malmquist Index (MI) were performed on a sample of 71 Italian 3PL providers. The results led to identify the best-in-class companies, i.e. 3PL providers that are able to respond to shippers' requirements through a better exploitation of efficiency or innovation with respect to the others competitors. Specifically, DEA scores allowed the measurement of the companies' efficiency for each year, taking into consideration also the impact of economies of scale, and the breakdown of MI facilitated the understanding of the efficiency change over time and the evaluation of the companies' innovation. The impact of some company features (i.e. industry focus and size) on efficiency and innovation was also analysed in order to reach a deeper understanding of the results.

Then, the results were discussed and validated with some of the 3PL providers included in the sample thanks to the authors' relationship with such companies within the activities of the Observatory of Contract Logistics, a permanent initiative launched in 2011 by the School of Management of Politecnico di Milano for doing research on the themes of logistics outsourcing, involving each year about 40 logistics service providers (http://www.contractlogistics.it).

In order to address the fourth research objective, a case study research were conducted on a sample of the best-in-class companies (i.e. 2). Such approach were considered the most appropriate methodology for validating the quantitative analysis and developing an in-depth knowledge the phenomenon (Yin 2013). 
Details on DEA-based models (i.e. CCR and BCC models and MI), the dataset and the case study methodology are reported below.

\subsection{CCR and BCC Models}

The DEA models applied are CCR (Charnes, Cooper, and Rhodes 1978) and BCC (Banker, Charnes, and Cooper 1984). These two models differs in the returns to scale assumption: the former considers constant returns to scale of activities, whereas the BCC model considers variable returns to scale, mitigating the impact of economies of scale on the efficiency (Min, DeMond, and Joo 2013). We chose to perform both CCR and BCC models as it is assumed that 3PL provider' efficiency is affected by the exploitation of the economies of scale.

We adopted the output oriented approach - instead of the input oriented one - since 3PL providers' resources such as company-owned vehicle fleet or warehouses are often not flexible in the short term and, as a result, the main practices adopted in the 3PL industry aim to optimise the use of such resources instead to minimise them. Consider $n$ DMUs and let $s$ and $m$ the number of outputs and inputs, respectively, the output oriented CCR and BBC dual models can be defined as follows:

CCR:

$$
\begin{array}{lr}
\max : \delta_{\mathrm{o}}+\varepsilon\left[\sum_{\mathrm{i}=1}^{\mathrm{m}} \mathrm{s}_{\mathrm{i}+} \sum_{\mathrm{r}=1}^{\mathrm{s}} \mathrm{s}_{\mathrm{r}}^{+}\right] & \\
\text {s.t. }-\delta_{o} y_{r 0}+\sum_{j=1}^{n} \lambda_{j} y_{r j}-s_{r}{ }_{r} \geq 0 & r=1, \ldots s \\
x_{i 0}-\sum_{j=1}^{n} \lambda_{j} x_{i j}-s_{i}^{-} \geq 0 & i=1, \ldots m \\
\lambda_{j,} s_{i,}^{-} s_{r}{ }_{r} \geq 0 &
\end{array}
$$


BCC:

$\max : \delta_{\mathrm{o}}+\varepsilon\left[\Sigma_{\mathrm{i}=1}^{\mathrm{m}} \mathrm{S}_{\mathrm{i}+}^{-} \Sigma_{\mathrm{r}=1}^{\mathrm{s}} \mathrm{S}_{\mathrm{r}}^{+}\right]$

s.t. $-\delta_{o} y_{r 0}+\sum_{j=1}^{n} \lambda_{j} y_{r j}-s_{r}^{+} \geq 0$

$r=1, \ldots s$

$x_{i 0}-\sum_{j=1}^{n} \lambda_{j} x_{i j}-s_{i}^{-} \geq 0$

$i=1, \ldots m$

$\sum_{j=1}^{n} \lambda_{j}=1$

$\forall j, i, r$

$\lambda_{j}, s_{i,}^{-} s_{r}^{+} \geq 0$

Where:

$y_{r j}$ and $x_{i j}=$ amount of output $r$ or input $i$ used by DMU $j$, respectively

$\lambda_{j}=$ weight given to $\mathrm{DMU} j$

$s^{+}{ }_{r}$ and $s_{i}^{-}=$slack variable of output $r$ and input $i$, respectively

$\varepsilon=$ small positive number

By solving the CCR and BCC models $n$ times, the 'overall' and 'technical' efficiency scores of each DMU (i.e. $1 / \delta_{o} \in[0,1]$ ), respectively, can be obtained. An efficiency score of 1 indicates that the DMU belongs to the efficiency frontier, while an efficiency score minor than 1 indicates that the DMU is not efficient compared to the frontier DMUs. Note that the efficiency score is obtained by the optimal values assigned to the weights, treated as unknown variables, related to each input and output. For further details about the models' formula, see Coelli (1996).

Thanks to the convexity restriction (Equation 2.3), the BCC model overcomes the constant returns to scale assumption of the CCR model and breaks up the overall efficiency score of a DMU into technical efficiency and scale efficiency (i.e. ratio between overall and technical efficiency).

Therefore, BCC model provides information about to what extent the size of the DMU is adequate to achieve the economies of scale. The optimal scale (named Most Productive Scale Size) 
for a DMU is that dimension such that economies of scale have been already fully exploited and diseconomies have not presented yet. This condition is verified when a DMU obtains the same score in both overall and technical efficiency evaluation. In such case, the DMU experiences neither increasing (irs) nor decreasing $(d r s)$ economies of scale but has reached the ideal scale in which is able to optimally exploit its resources. If a DMU experiences irs, it means that economies of scale are still to be exploited by increasing its size. Vice versa, if a DMU experiences $d r s$, it means that the DMU is oversized compared to its optimal scale.

\subsection{DEA-based Malmquist Index}

The Malmquist Index (MI) has been applied to measure the efficiency change from period $t$ to $t+1$ and evaluate company innovation. This index is based on the same DEA linear programming models and can be expressed as:

$$
\mathrm{MI}^{\mathrm{t}, \mathrm{t}+1}=\left(\mathrm{MI}^{\mathrm{t}} * \mathrm{MI}^{\mathrm{t}+1}\right)^{1 / 2}=\left[\mathrm{D}^{\mathrm{t}}\left(\mathrm{x}^{\mathrm{t}+1}, \mathrm{y}^{\mathrm{t}+1}\right) / \mathrm{D}^{\mathrm{t}}\left(\mathrm{x}^{\mathrm{t}}, \mathrm{y}^{\mathrm{t}}\right) * \mathrm{D}^{\mathrm{t}+1}\left(\mathrm{x}^{\mathrm{t}+1}, \mathrm{y}^{\mathrm{t}+1}\right) / \mathrm{D}^{\mathrm{t}+1}\left(\mathrm{x}^{\mathrm{t}}, \mathrm{y}^{\mathrm{t}}\right)\right]^{1 / 2}
$$

Given the output oriented approach, productivity growth corresponds to a MI greater than one and productivity decline corresponds to an index smaller than one. The MI implies the application of CCR DEA model as it requires the estimation of two single period efficiency scores, $D^{t}\left(x^{t}, y^{t}\right)$ and $D^{t+1}\left(x^{t+1}, y^{t+1}\right)$, and two mixed-period efficiency scores, $D^{t}\left(x^{t+1}, y^{t+1}\right)$ and $D^{t+1}\left(x^{t}, y^{t}\right)$, assuming constant returns to scale.

The contribution of Färe, Grosskopf, and Lovell (1994) shows the break-up of MI into the product of efficiency change $(E C)$ and technology change $(T C)$, as reported in Equation (4):

$$
\begin{aligned}
& \mathrm{MI}=\mathrm{D}^{\mathrm{t}+1}\left(\mathrm{x}^{\mathrm{t}+1}, \mathrm{y}^{\mathrm{t}+1}\right) / \mathrm{D}^{\mathrm{t}}\left(\mathrm{x}^{\mathrm{t}}, \mathrm{y}^{\mathrm{t}}\right) *\left[\mathrm{D}^{\mathrm{t}}\left(\mathrm{x}^{\mathrm{t}}, \mathrm{y}^{\mathrm{t}}\right) / \mathrm{D}^{\mathrm{t}+1}\left(\mathrm{x}^{\mathrm{t}}, \mathrm{y}^{\mathrm{t}}\right) * \mathrm{D}^{\mathrm{t}}\left(\mathrm{x}^{\mathrm{t}+1}, \mathrm{y}^{\mathrm{t}+1}\right) / \mathrm{D}^{\mathrm{t}+1}\left(\mathrm{x}^{\mathrm{t}+1}, \mathrm{y}^{\mathrm{t}+1}\right)\right]^{1 / 2} \\
& =\mathrm{EC} * \mathrm{TC}
\end{aligned}
$$

The ratio outside the brackets measures the Efficiency Change $(E C)$ between periods $t$ and $t+1$. The square root of the term inside the brackets measures the Technical Change (TC), or frontier shift, between the same periods. 
$E C$ is the ratio of the efficiency scores between periods $t$ and $t+1$ and indicates how a DMU comes close (or away) from efficiency frontier in the periods considered (the so-called catch-up effect). $E C>1$ indicates progress in relative efficiency from period $t$ to $t+1$, while $E C=1$ and $E C<$ 1 indicate the status quo and decline in efficiency, respectively. $E C$ can be further break-up in Pure Efficiency Change (PE ch.) and Scale Effect Change (SE Ch.). The former indicates the variation of the efficiency scores computed according to the BCC model, while the latter represents the variation of the scale efficiency.

The expression inside the brackets $(T C)$ indicates the technical progress defined by the shift of the frontier between $t$ and $t+1$, measured at two different points. It is the geometric average of the two indexes of technical progress: the first considers the input-output combination in period $t+$ 1 , and is computed as ratio of the distance to the frontier in period $t$ and the period $t+1$; the second term is computed in the same way but considering the input-output combination in period $t$. This component captures the average effect of technological progress / regress in the sample considered. $T C>1$ indicates a technological progress of the sample from period $t$ to $t+1$, while $T C=1$ and $T C$ $<1$ indicate respectively the status quo and decay of the technological progress of the sample.

For each DMU, TC merely indicates whether, at its input-output combination, the frontier shifted outwards or inwards, but not whether that DMU was located on the frontier and contributed to that technological progress. According to Färe, Grosskopf, and Lovell (1994), in order to find those DMUs that can be considered 'innovative' (i.e. DMUs that shifted the frontier to more productive levels over time) it is also necessary to see if the DMUs lies on the frontier in period $t+$ 1. Therefore, a DMUs can be considered 'innovative', between period $t$ and $t+1$ if the conditions in Equation (5) are satisfied:

$$
D^{t+1}\left(x^{t+1}, y^{t+1}\right)=1 \text { and } D^{t}\left(x^{t+1}, y^{t+1}\right)>1
$$

Given this definition of 'innovative' DMUs, it is clear that this methodology does not identify all the types of innovation (e.g. introduction of new services), but definitely it allows 
identifying innovations that increase the 3PL provider's efficiency, also named pure internal innovations according to Wallenburg (2009).

\subsection{Model Specifications and Data}

CCR, BCC models and MI were conducted by applying a linear program formulated in equations (1)-(5) to the dataset and by using DEAP software 2.1 (Coelli 1996).

A crucial step in using DEA is the selection of the appropriate input and output measures that can be aggregated into an overall performance index to mitigate the risk of obtaining biased results and losing relevant information. In line with the previous works applying DEA in the 3PL industry (Zhou et al. 2008; Min and Joo 2006), we selected four measures as inputs that represent physical resources and financial performance: (i) net fixed assets (including properties and equipment), (ii) salaries and wages of employees, (iii) operating expenses (other than salaries and wages) and (iv) current liabilities. The first measure has been included to reflect the efficiency of asset management, whereas salaries and wages reflect the efficiency of direct investment in human resources. In the same way, operating expenses, that include numerous variable costs such as fuel or sub-contracted services, reflect other key resources for logistics activities. Current liabilities reflect the financial health of 3PL providers and, therefore, to same extent their investment capability. As output measure, EBITDA (Earnings Before Interest, Taxes, Depreciation and Amortization) was selected.

Models were applied to a sample of Italian 3PL providers. The role of 3PL providers has evolved over time, as highlighted by Leuschner et al. (2014). Our analysis includes 3PL providers defined, according to Selviaridis and Spring (2007), as companies that are able to perform both the execution and the planning of warehousing and transportation activities till the entire logistics process, managing a number of 3PL relationships simultaneously. Since a database containing the contact details of all the 3PL providers operating in Italy (i.e. the population) does not exist, we 
used a non-probability convenience sampling frame, based on the Database of Observatory of Contract Logistics containing 110 3PL providers operating in Italy with revenues higher that $€ 10$ million. Because of the problem of generalisation, the data will not allow definitive findings to be extended to all the population, but they could provide interesting sights of the problem and be a springboard for further research (Bryman and Bell 2011).

The values of input and output measures were obtained thanks to the access to the AIDA database provided by Bureau Van Dijk. Data refer to the period from 2009 to 2012.

Before applying DEA models, the dataset was modified in order to handle missing data and negative DMU values issues. All companies with at least one missing input or output value were deleted according to the approach suggested in the literature (von Hirschhausen and Cullan 2010). This reduction led to a sample of 71 Italian 3PL providers. All the negative values were replaced by a very small number compared to the others (i.e. 1) according to the approach suggested by Bowlin (1998). This approach were selected instead of the more common one, proposed for example for the BCC model by Ali and Seiford (1990), as our models are not translation invariant with respect to the output (i.e. EBITDA).

Prior to testing the proposed DEA models, we also assured that the number of DMUs was at least three times of the total number of inputs and outputs (Bowlin 1998) to ensure the discriminatory power of the model and therefore significant results. Table 1 presents a summary of the input and output measures for the 71 Italian 3PL providers.

[Table 1 near here]

As above-mentioned, we further classified 3PL providers according to the industry focus and size. To discriminate medium- and large- size (MS and LS, respectively) 3PL providers, we used an annual revenues threshold of $€ 100$ million, while to define the industry focus we considered the amount of revenues derived from the different industries. Specifically, 3PL providers with more than $70 \%$ of their revenues focussed at most on three specific industries have been 
considered 'industry focussed' (IF), vice versa 'industry unfocussed' (IU). Table 2 shows how the 3PL providers included in the analysis are distributed in the four subsamples.

[Table 2 near here]

\subsection{Case Study}

In order to provide insights on the strategies pursued by 3PL providers to reach high scores of efficiency and innovation, a case study approach were adopted. Multiple case studies were performed to capture, even partially, the several ways for pursuing efficiency or innovation followed by 3PL providers with heterogeneous characteristics. Specifically, we decided to focus on the 3PL providers that, within the best-in-class DMUs identified from the DEA models application, have been able to successfully pursue both efficiency and innovation. Such latter companies have been able to both maintaining high efficiency rates in terms of input-output ratio and performing efforts in terms of cost and human resources needed to introduce improvements and innovative solutions. It must be acknowledged that management practices that lead to efficiency or innovation are generally different and often contradictory: efficiency usually requires standardization and conformity to rules and procedures, while innovation requires flexibility, breaking from existing paradigms, autonomy, risk taking, and tolerance for mistakes in the pursuit of new and prospective knowledge (Naveh 2005). As such, it has been recognized interesting to focus on the 3PL providers that have been able to successfully pursue both efficiency and innovation.

Within the identified sample, the selection of the cases was driven by the availability of the companies to take part to the research. Two companies gave their consent and hereinafter are referred to as $\mathrm{A}$ and $\mathrm{B}$ for confidentiality reasons.

The detailed description of the companies' characteristics is presented in the section 4.1. Data were collected through semi-structured interviews, to ensure the cross-case comparability. Due to time and cost matters, interviews were conducted by phone. As suggested by Glaser and Strauss 
(1967), instruments (recorder and written notes) were used to consolidate the collected information. Secondary sources were also used to collect information about the companies and the contexts in which they operate.

\section{The Quantitative Evaluation of Efficiency and Innovation}

Overall, technical and scale efficiency were assessed by applying CCR and BCC models. Next, the MI allowed the assessment of the technical efficiency change over time (through the $P E$ ch. term) and the identification of the innovative companies through the combined analysis of innovation and technical efficiency scores. The results were further analysed distinguishing by size and industry focus. Finally, the efficiency and innovation cross-analysis led to the identification of the best-inclass 3PL providers. The following subsections discuss the main findings of the research.

\subsection{Efficiency Analysis}

As shown in Table 3, the overall efficiency analysis reveals, first, that on average the $10 \%$ of the Italian 3PL providers presents the highest inputs to outputs ratio and therefore composes the efficiency frontier (i.e. companies with CCR efficiency score $=1$ ), while the majority of the industry (i.e. $83 \%$ of the companies, on average) operates inefficiently such that the efficiency scores are less than 0.8 . Second, the presence of inefficiencies in the industry is substantially stable over time as illustrated by the average and median CCR efficiency scores that are around 0.42 and 0.34 , respectively, in all the years considered.

[Table 3 near here]

As mentioned earlier, the overall efficiency scores are affected by the company size and the ability to exploit the related economies of scale. Such impact on the efficiency is mitigated by the 
BCC model that allows obtaining the technical efficiency. Table 4 reports the summary of technical efficiency scores.

[Table 4 near here]

The number of efficient DMUs is higher compared to the CCR model results. Taking into account the size and the ability to exploit the related economies of scale, on average, the $25 \%$ of the Italian 3PL providers operates with an optimal inputs to outputs ratio (i.e. companies with BCC efficiency score $=1$ ). Like in the CCR model results, the average technical efficiency scores is substantially constant over time, around 0.56 , and reveals a wide disparity in performance, since the $67 \%$ of the companies reaches a score less than 0.8 . However, it seems that the percentage of efficient 3PL providers slightly increases across the period 2009-2012 (from $23 \%$ in 2009 to $27 \%$ in 2012). Moreover, the number of non-efficient DMUs with efficiency scores higher or equal to 0.8 first strongly increases between 2009 and 2010 (from 5 to 11) and then decreases from 2010 to 2011 (11 to 4).

As far as the scale efficiency (i.e. ratio between overall and technical efficiency) is concerned, Table 5 shows that on average, only the $17 \%$ of the DMUs operates at the Most Productive Scale Size, i.e. that dimension such that economies of scale are already all been exploited and diseconomies have not presented yet. On average, the $27 \%$ of the companies experiences increasing return to scale, while a large part of the sample (i.e. 56\%) exploits diseconomies related to their size. An explanation is that fixed cost and structures are not rewarded from the operational activities.

\section{[Table 5 near here]}

Looking at the multi-period analysis of each DMU's efficiency score, the results show that only a limited number of DMUs (i.e. 6) lies on the technical efficiency frontier since 2009 to 2012. The Pure Efficiency Change ( $P E$ ch.) term of MI highlights that on average the $44 \%$ of DMUs increases in technical efficiency over the years, against 39\% that declines in efficiency between 
2009 and 2012, with the worst performance between 2010 and 2011, where the 54\% of DMUs decreases in technical efficiency (Table 6). This efficiency loss has only been partly regained in 2012, where the $48 \%$ of the 3PL providers have increased in technical efficiency.

[Table 6 near here]

The analysis of the results distinguishing by the type of 3PL providers shows that the majority of the efficient DMUs has a strong industry focus, on average $72 \%$ (Table 7). This latter result is also statistically supported as the difference between the central tendency of the average efficiency score among focussed and unfocussed 3PL providers is statistically significant at a 0.05 level using the non-parametric rank-sum test $(p$-value $=0.0311)$.

[Table 7 near here]

This evidence suggests that the strong industry specialisation can facilitate an efficient usage of inputs through both the specific expertise developed from earlier experiences or existing relationships (e.g. Hertz and Alfredsson 2003) and the spreading of investment in specialised assets or resources between different shippers (Logan 2000). Moreover, the focus on niche markets, with a limited service offering, emerges as a common pattern among efficient 3PL providers also in the Min, DeMond, and Joo (2013) contribution that compared 24 leading 3PL providers in North America.

Furthermore, our results reveal that the strong industry focus is also the characteristics of the $75 \%$ of the DMUs operating at the Most Productive Scale Size, highlighting that such industry specialisation can facilitate the exploitation of economies of scale.

Looking at the size, the results suggest that the positive relation between the size and the ability to exploit economies of scale is not always true: the $83 \%$ of the DMUs operating at the Most Productive Scale Size presents annual revenues lower than $€ 100$ million. Such evidence is also in line with Min, DeMond, and Joo (2013), that highlight how the size growth in the case for instance 
of rapid expansion of the business scope through mergers and acquisitions or globalization, may hurt (especially in the short-term) the efficiency leading to diseconomies of scale.

\subsection{Identification of the Innovative 3PL Providers}

As far as the 3PL providers' innovation is concerned (Table 8), innovative DMUs, i.e. those that have contributed to the positive shift of the technical efficiency frontier between the period $t$ and $t+$ 1 and lies on such frontier in period $t+1$, are $10.3 \%$ on average. This small number of 3PL providers that have introduced process innovation to improve their ability to transform inputs in outputs (i.e. their ability to be efficient) confirms the perception of a mature industry in which the efficiency frontier moves forward slowly (Langley and Capgemini 2015).

[Table 8 near here]

Looking at the differences in innovation among industry focussed and unfocussed companies or medium- and large- size companies (Table 9), improvements and process innovations seem mostly pushed forward by industry focussed 3PL providers as, on average, 6 out of 7.4 innovative DMUs are industry focussed. This means that the industry specialisation can also though the growth of specific knowledge - facilitates the development of best practices to improve internal processes. As far as the size is concerned, it seems that large-size 3PL providers are struggling to introduce process innovations. This evidence suggests that a leaner organisation can allow faster decision-making processes to improve and introduce new best practices to meet the customers' needs.

[Table 9 near here] 


\subsection{Efficiency and Innovation Cross-analysis}

In order to find best-in-class companies in terms of both efficiency and innovation, the Italian 3PL providers under examination have been classified according to:

- Efficiency degree, i.e. 'High' if the BCC efficiency score is 1 for at least 2 year out for 4, otherwise 'Low';

- Innovation degree, i.e. 'High' if a DMU is 'innovative' at least for 2 period out of 3 , otherwise 'Low'.

As Figure 1 shows, 13 companies have been able to maintain a leader position from the efficiency side but without contributing to shift the efficiency frontier over time by introducing internal process innovations. Only $63 \mathrm{PL}$ providers have been able to pursue, continuously over time, both efficiency and process innovation.

[Figure 1 near here]

Both of these two clusters can be used for benchmark activities to understand the best practices adopted and the growth directions of the industry. Therefore, it is interesting to understand their characteristics. 13 out of these 19 3PL providers are strongly industry focussed and only 3 can be considered large-size 3PL providers, confirming the evidence discussed above. Nevertheless, analysing their characteristics in terms of input (Table 10), a strong diversification emerges. Indeed, the average composition of their inputs shows that they have pursued these objectives with different business models.

[Table 10 near here]

For instance, DMU No. 12 pursues an 'asset-based' strategy (Africk and Calkins, 1994; Tezuka, 2011), with more the $60 \%$ of its input related to fixed assets (e.g. own fleet or warehouses). A similar strategy is pursued by DMU No. 17 but focussing on asset as human resources, both at operating and managerial corporate level, as the relative weight of salaries and wages reveals. Vice 
versa DMU No. 68, with only the $8 \%$ of its input related to fixed asset or human resources, shows a strong 'non-asset based' strategy, where about the $80 \%$ of the inputs is directed towards operating expenses, such as sub-contracted services. Beside these polar opposites, a wide range of intermediate positions in terms of asset management strategy can be found; an example is DMU No. 28, where fixed assets and operating expenses are balanced.

This evidence emphasises the heterogeneity of the 3PL industry, where there is not a unique business model ensuring efficiency and process innovation and all the studies and benchmarking activities have to be careful in investigating best practices and business models.

\section{Case Study Results}

The quantitative assessment presented above led to the identification of 6 3PL providers that resulted best-in-class in both efficiency and innovation as they were able to introduce innovations that contributed to the evolution of the efficiency frontier and the achievement of higher efficiency levels.

The results of the two case studies are reported below. They aim to corroborate the quantitative results through the investigation of the strategies adopted by these latter companies to enhance efficiency and introduce process innovation.

\subsection{Summary of the Case Study Profile}

Table 11 summarises the case study profile.

[Table 11 near here]

Company A is an Italian family-owned 3PL provider operating mainly in the food and large retail industry. Beyond the Italian borders, this company has opened in the last decade a number of subsidiaries in France but it seems still little interested in pushing over the international expansion. 
The annual revenues show an important growth rate in the period analysed (from $€ 34$ million in 2009 to $€ 61$ million in 2012); moreover the acquisition of a courier company in the 2014 has increased the revenues up to more that $€ 100$ million.

A significant percentage of the revenues (i.e. about $80 \%$ in 2012) entails the providing of integrated logistics services in which the entire logistics process of the shipper is managed (or at least a large portion of it). As such, the company is involved at the planning/design level with the suppliers and the length of outsourcing agreements is generally long.

Company A shows a substantially stable level of margin (expressed by the EBIT/revenues ratio; i.e. around $9 \%$ ) higher than the average value of the Italian industry, that is around $2.5 \%$.

Looking at the choices about the transport asset management, the company has chosen a mixed strategy. It owns a truck fleet to fulfil almost the half of the transport demand and relies heavily on the sub-contracting for warehousing activities to suppliers that provide the warehouse personnel almost exclusively to it.

Company B operates mainly in industrial sectors such as aerospace, energy, electronics and defence. The company has born as the logistics branch of one of the biggest Italian industrial firm and nowadays provides services to both such parent company and other shippers. Founded in 2002, Company B has almost doubled its annual revenues between 2009 and 2012, thanks to both the extension of existing agreements and the acquisitions of new customers, and currently presents an average turnover about $€ 70$ million.

More than the $80 \%$ of its revenues concerns the providing of integrated logistics services, often linked to consultancy services for the re-design of the customers' supply chain or ad hoc transport solutions for oversize loads. The margin is higher than the average of the Italian industry and it is substantially stable, around $12 \%$. 
The asset management strategy of Company B should be classified as an 'hybrid' since the company has chosen to rely heavily on the sub-contracting for what concerns the fixed-assets (as trucks, handling equipment for oversize loads and warehouses), while a significant portion of the warehouse staff is directly hired, as the input average composition shows.

\subsection{Strategies to Enhance Efficiency}

The positioning of Company A in the 'high efficiency' side of Figure 1, obtained achieving each year the highest efficiency score, reflects the development over time of strong flow management capabilities, in terms of planning and controlling transport and warehouse activities, to achieve efficiency goals. In line with Berglund et al. (1999), Hert and Alfredsson (2003) and Lai, Cheng, and Yeung (2004) such capabilities play a key role in the design of the logistics services for shippers.

Specifically, Company A has been particularly successful in achieving these goals thanks to the adoption of specific strategies, that to date are hardly implemented in the Italian context: first, the development and the introduction of forecasting and planning tools and, second, the ability to synergic manage shippers with a complementary seasonality of the products. In such ways, Company $\mathrm{A}$ is able to dynamically manage peaks and dips in demand without the need to make investments or divestments in fixed assets or personnel, by allocating transport and warehouse resources among shippers according to their demands and their needs (Hsiao et al. 2010). Moreover, another characteristic that distinguishes this company from the majority of the 3PL providers is the ability to maintain a strong control of the activities, even if subcontracted. About $50 \%$ of its subcontractors belongs to the same holding company of Company A. Compared to the case of external subcontractors, such control significantly contributes to the good planning of the activities and the good management of the practices implemented. 
Also Company B achieved the highest efficiency score every year considered, positioning itself in the 'high efficiency' side of Figure 1. This goal has been realised thanks to the successful exploitation of learning economies, indeed, through the improvement of specific knowledge about the peculiarities of the industry tackled, Company B has been able to create a competitive advantage to its customers by offering know-how, expertise and highly skilled people otherwise hard to find externally or of expensive internal development. According to Tezuka (2011) such capability allows specialised 3PL providers to engage in logistics activities more cost-efficiently. Specifically Company B has been able to share the specific knowledge acquired between different shippers thanks to the development and the transfer of best practices. A key role in such managerial solution has been played by the directly hired warehouse staff that has been trained and motivated to transfer its experience and company's practices to solve and/or improve the customer's logistics process.

\subsection{Strategies to Introduce Process Innovations}

Beside the strategies pursued in order to achieve the efficiency, both Company A and B have had an active role also in the positive shift of the technology frontier, by introducing process innovations in each year of the analysis. Such contribution to the technology frontier improvement allowed the companies to gain the 'high innovation' positioning in Figure 1. As per Sauvage (2003), such technological effort to improve the internal efficiency, i.e. the ability to implement new organisational and technical solutions to improve the management of flows, has become a key variable and a significant means of differentiation in the 3PL market.

Analysing such ability, unlike the majority of the industry, Company A has been able to successfully contribute to the technological change specifically thanks to (i) the presence of a process re-engineering team to support continuous improvement and revise new shippers' processes and (ii) the establishment of partnerships with technology providers to introduce technological innovations. More in detail, the company has just introduced low consumptions trucks, by the use 
of multi-fuel engines (diesel and methane) and electric- or methane-powered vehicles for the last mile distribution, confirming the prevalence of innovative solutions related to the transport activities in the logistics field.

At this regard, company B has adopted a different approach by establishing partnerships directly with customers to introduce process innovations within the single specific relationship. For instance, the more recent innovative project that the company has successfully undertaken has aimed to develop unique identifiers to be assigned to the smallest packaging unit, to ensure the traceability throughout all the supply chain and protect the products against counterfeiting.

\subsection{A Common Behavioural Pattern in Pursuing both Efficiency and Innovation}

Both of the exanimated companies have been able to successfully pursue efficiency and innovation by adopting strategies consistent with both the perspectives. Although it emerges that such strategies can be different in nature, three common aspects between the two cases can be identified. First, such strategies are specifically focussed on the needs and the processes of the shippers. Indeed, the deep analysis of shippers' needs and processes has allowed the companies to manage them efficiently (e.g. as per Company A with the analysis of the seasonality of the products for a synergic management of the shippers) and continuously improve their standard (e.g. as per Company B that has undertaken partnerships directly with shippers to introduce innovations). According to Hertz and Alfredsson (2003) such 'customer adaptation' is one of the main tasks for the 3PL providers' strategic development.

Second, both of the companies are strongly industry focussed and the high-specialised skills acquired in the specific industries have allowed developing best practices, transferrable between shippers.

Third, the cases show a strong management commitment that pushed the companies at all the corporate levels. Such commitment entails, for instance, the promotion of training courses and 
programs to improve both knowledge and awareness (Company B), the presence of inter-functional teams aimed to share knowledge and improve practices (Company A) or the presence of an incentives system promoting company efficiency and innovation (Company A and B).

These three key aspects affect each other. Indeed, the in depth knowledge of shippers' processes leads to knowledge development in the corresponding industry. In turn, the market knowledge facilitates to perform better in customer adaptation and transfer of knowledge among shippers. This process yields to enhance the current skills and develop new competences.

The management commitment plays a key role on the strategies adopted as it makes decisions, allocate resources, change organisation and so on. For instance, the commitment can support the diffusion of the best practices and promote knowledge sharing initiatives.

Therefore, the empirical evidence shows, beside the presence of different specific strategies adopted to enhance efficiency or introduce innovation, a common behavioural pattern characterising the two cases: the acquisition of specific knowledge for each shipper and specific skills for each industry together with the management commitment significantly contribute to the success of the specific strategies adopted.

In summary, the case study results presented in this section enhance the fact that companies adopt specific strategies to be efficient and innovative, corroborating the scores and the identification of the best-in-class companies obtained through DEA. However, as only 2 cases were performed, results about what are the strategies adopted to pursue efficiency or innovation (or both simultaneously) can be considered as a springboard for future research on the 3PL providers' business models but they can not be generalised. 


\section{Conclusions and Extensions}

The paper presents the results of a mixed-method study of efficiency and process innovation in the Italian 3PL industry. First, it provides the quantitative measurement of 3PL providers' efficiency and innovation based on DEA models (i.e. CCR, BCC models and MI). Second, it explores the strategies through which best-in-class companies have been able to reach high scores of efficiency and innovation, based on a case study research. Performing such analysis in the 3PL industry, this paper is the first to (i) study jointly the assessment of efficiency and innovation and (ii) corroborate and link the quantitative results obtained through DEA models with the 3PL providers' strategies.

As far as the efficiency analysis is concerned, the findings show an industry where the technical efficiency frontier is composed of the $25 \%$ of the 3PL providers, the average efficiency score is substantially constant over time and the majority of the industry operates experiencing diseconomies related to the size. The inter-periodic analysis reveals that the sector has faced a general efficiency loss in 2011, only partly regained in 2012.

With reference to the innovation assessment, on average, the $10 \%$ of the 3PL providers has introduced process innovation to improve their efficiency in the period analysed.

Overall, results from the efficiency and innovation analysis provide useful insights for benchmarking activities. 13 3PL providers have been found as efficiency leaders, while the crossanalysis has allowed identifying 6 best-in-class companies from both the efficiency and innovation side. The majority of such 19 companies is medium-size and has a strong industry focus, that can facilitates the efficient usage of inputs and the development of best practices through the exploitation of both economies of scale and learning economies. Despite these shared features, their input composition indicates a strong diversification of the business models adopted. Companies with similar characteristics in terms of size and industry focus present different behaviours, i.e. adoption of asset- or non asset- based strategies. 
Finally, through the case study research, it has been possible to provide empirical-based evidence on the strategies through which best-in-class companies have been able to reach high DEA scores. The analysis witnesses the presence of different specific strategies adopted to enhance efficiency (such as strong flow management capabilities and control of the activities, even if subcontracted) or introduce innovation (such as presence of a process re-engineering team to support continuous improvement or partnerships with technology providers to introduce technological innovations). Additionally, case study results highlight that the success of such specific strategies is significantly affected by the acquisition of specific knowledge for each shipper and specific skills for each industry, together with the management commitment.

From a practical viewpoint, this research is of interest for both 3PL providers and shippers. On one side, the study can help 3PL providers in understanding the best practices adopted and the growth directions of the industry thanks to the benchmarking analysis. Such insights support them in improving their services and in a better understanding of how efficiency- and innovation-based strategies can be pursued together for competitiveness. On the other side, shippers are supported when selecting their 3PL providers as the results can enhance an understanding of the differences among 3PL providers and the alternative ways through which 3PL providers can create value for their logistics processes.

Based upon the results of our study, further research may be built. The methodology provided in this paper can be followed to assess the current state of the 3PL industry in other countries and, therefore, to extend the research scope of the benchmarking analysis. Moreover, this study can be developed towards an additional analysis on how the best-in-class 3PL providers' business models are related to the value created for the shippers, deepening the results of the case studies. 


\section{References}

Ali, A. I., and L. M. Seiford .1990. "Translation Invariance in Data Envelopment Analysis.” Operations Research Letters 9 (6): 403-405.

Africk, J. M., and C. S. Calkins. 1994. "Does Assets Ownership Means a Better Service?" Transportation and Distribution 35 (5): 49-61.

Asthana, S. 2013. "Performance Measurement Variables in Third Party Logistics (3PL) - a Literature Review.” International Journal of Research in IT \& Management 3 (1): 17-23.

Banker, R. D., A. Charnes, and W. W. Cooper. 1984. "Some Models for Estimating Technical and Scale Inefficiencies in Data Envelopment Analysis." Management Science 30 (9): 10781092.

Berglund, M., P. van Laarhoven, G. Sharman, and S. Wandel. 1999. "Third-Party Logistics: Is There a Future?" International Journal of Logistics Management 10 (1): 59-70.

Bolumole, Y. A. 2003. "Evaluating the Supply Chain Role of Logistics Service Providers." International Journal of Logistics Management 14 (2): 93-107.

Bowlin, W. F. 1998. "Measuring Performance: An Introduction to Data Envelopment Analysis (DEA)." Journal of Cost Analysis 7: 3-27.

Bryman, A., and M. Bell. 2011. Business Research Methods - 3rd Edition. New York: Oxford University Press.

Carbone, V., and M. A. Stone. 2005. "Growth and Relational Strategies Used by the European Logistics Service Providers: Rationale and Outcomes." Transportation Research Part E 41 (6): 495-510.

Caves, D., L. Christensen, and W. Diewart. 1982. "The Economic Theory of Index Numbers and the Measurement of Input, Output, and Productivity." Econometrica 50 (6): 1393-414.

Charnes, A., W. W. Cooper, and E. L. Rhodes. 1978. "Measuring the Efficiency of Decision Making Units.” European Journal of Operational Research 2 (6): 429-444.

Coelli, T. 1996. A Guide to DEAP Version 2.1: A Data Envelopment Analysis Computer Program. Armidale (Australia): Department of Econometrics, University of New England.

Cook, W. D., and L. M. Seiford. 2009. "Data Envelopment Analysis (DEA) - Thirty Years On." European Journal of Operational Research 192 (1): 1-17.

Cullinane, K. P. B., and T.-F. Wang. 2006. "The Efficiency of European Container Ports: a CrossSectional Data Envelopment Analysis." International Journal of Logistics: Research and Applications 9 (1): 19-31. 
Färe, R. S., S. Grosskopf, and C. A. K. Lovell. 1994. Production Frontiers, Cambridge: Cambridge University Press.

Glaser, B. G., and A. L. Strauss. 1967. The Discovery of Grounded Theory: Strategy for Qualitative Research, Chicago: Aldine.

Hertz, S., and M. Alfredsson. 2003. "Strategic Development of Third Party Logistics Providers." Industrial Marketing Management 32 (2): 139-149.

von Hirschhausen, C., and A. Cullmann. 2010. "A Non-Parametric Efficiency Analysis of German Public Transport Companies." Transportation Research Part E 46 (3): 436-445.

Hsiao, H. I., R. G. M. Kemp, J. G. A. J. van der Vorst, and S. W. F. Omta. 2010. “A Classification of Logistic Outsourcing Levels and their Impact on Service Performance: Evidence from the Food Processing Industry.” The International Journal of Production Economics 124 (1): $75-86$.

Lai, K., T. E. Cheng, and A. C. Yeung. 2004. “An Empirical Taxonomy for Logistics Service Providers." Maritime Economics \& Logistics 6: 199-219.

Large, R.O., N. Kramer, and R. C. Hartmann. 2011. "Customer-Specific Adaptation by Providers and their Perception of 3PL-Relationship Success." International Journal of Physical Distribution and Logistics Management 41 (9): 822-838.

Langley, C. J. and Capgemini. 2015. "2015 Third-Party Logistics Study: The State of Logistics Outsourcing. Results and Findings of the 19th Annual Study." available at: http://www.3plstudy.com/ (accessed 7 July 2015).

Leuschner, R., C. R. Carter, T. J. Goldsby, and Z. S. Rogers. 2014. "Third-Party Logistics: a MetaAnalytic Review and Investigation of its Impact on Performance." Journal of supply chain management 50 (1): 21-43.

Lieb, R. and B. A. Bentz. 2005. "The North American Third Party Logistics Industry in 2004: the Provider CEO Perspective.” International Journal of Physical Distribution and Logistics Management 35 (8): 595-611.

Logan, M. S. 2000. "Using Agency Theory to Design Successful Outsourcing Relationship.” The International Journal of Logistics Management 11 (2): 21-32.

Malmquist, S. 1953. "Index Numbers and Indifference Surfaces.” Trabajos de Estatistica 4: 209242.

Makukha, K., and R. Gray. 2004. "Logistics Partnerships between Shippers and Logistics Service Providers: The Relevance of Strategy." International Journal of Logistics: Research and Applications 7 (4): 361-377. 
Miguéis, V. L., A. S. Camanho, E. Bjørndal, and M. Bjørndal. 2011. "Productivity Change and Innovation in Norwegian Electricity Distribution Companies." Journal of the Operational Research Society 63 (7): 982-990.

Min, H., and S. Joo. (2009), "Benchmarking Third-Party Logistics Providers Using Data Envelopment Analysis: an Update.” Benchmarking: An International Journal 16 (5): 572587.

Min, H., S. DeMond, and S. Joo. 2013. "Evaluating the Comparative Managerial Efficiency of Leading Third Party Logistics Providers in North America.” Benchmarking: An International Journal 20 (1): 62-78.

Min, H., Y.-H. Ahn, and T. E. Lambert. 2015. "Evaluating the Comparative Efficiency of Urban Mass Transit Systems: a Longitudinal Analysis of the Ohio Case.” International Journal of Logistics: Research and Applications 18 (6): 518-534.

Naveh, E. 2005. "The Effect of Integrated Product Development on Efficiency and Innovation." International Journal of Production Research 43 (13): 2789-2808.

Odeck, J. 2008. "The Effect of Mergers on Efficiency and Productivity of Public Transport Services.” Transportation Research Part A 42: 696-708.

O’Neill, L., M. Rauner, K. Heidenberger, and M. Kraus. 2008. “A Cross-National Comparison and Taxonomy of DEA-based Hospital Efficiency Studies.” Socio-Economic Planning Sciences 42: $158-189$.

Prockl, G., A. Pflaum, and H. Kotzab. 2012. “3PL Factories or Lernstatts? Value-Creation Models for 3PL Service Providers." International Journal of Physical Distribution and Logistics Management 42 (6): 544-561.

Pires, H. M., and E. Fernandes. 2012. "Malmquist Financial Efficiency Analysis for Airlines.” Transportation Research Part E 48 (5): 1049-1055.

Rajesh, R., S. Pugazhendhi, K. Ganesh, C. Muralidharan, and R. Sathiamoorthy. 2011. "Influence of 3PL Service Offerings on Client Performance in India." Transportation Research Part E 47 (2): 149-165.

Sauvage, Y. 2003. "The Relationship between Technology and Logistics Third-Party Providers." International Journal of Physical Distribution and Logistics Management 33 (3): 236-253. Selviaridis, K., and A. Norman. 2015. "Performance-based Contracting for Advanced Logistics Services: Challenges in its Adoption, Design and Management." International Journal of Physical Distribution and Logistics Management 45 (6): 592-617. 
Selviaridis, K., and M. Spring. 2007. “Third Party Logistics: a Literature Review and Research Agenda." International Journal of Logistics Management 18 (1): 125-150.

Sirilli, G., and R. Evangelista. 1998. “Technological Innovation in Services and Manufacturing: Results from Italian Surveys.” Research Policy 27 (9): 881-899.

Skjoett-Larsen, T. 2000. "Third Party Logistics - from an Interorganizational Point of View." International Journal of Physical Distribution and Logistics Management 30 (2): 112-127.

Soinio, J., K. Tanskanen, and M. Finne. 2012. "How Logistics-Service Providers can Develop Value-added Services for SMEs: a Dyadic Perspective.” International Journal of Logistics Management 23 (1): 31-49.

Talluri, S., F. Hug, and W. E. Pinney. 1997. “Application of Data Envelopment Analysis for Cell Performance Evaluation and Process Improvement in Cellular Manufacturing." International Journal of Production Research 35 (8): 2157-2170.

Tezuka, K. 2011. "Rationale for Utilizing 3PL in Supply Chain Management: A shippers' economic perspective." IATSS Research 35 (1): 24-29.

Thanassoulis, E. 1999. "Data Envelopment Analysis and its Use in Banking." Interfaces 29 (3): 113.

Vickery, S. K., C. Droge, T. P. Stank, T. J. Goldsby, and R. E. Markland. 2004. “The Performance Implication of Media Richness in a Business-to-Business Service Environment: Direct Versus Indirect Effects.” Management Science 50 (8): 1106-1119.

Wallenburg, C. M. 2009. "Innovation in Logistics Outsourcing Relationships: Proactive Improvement by Logistics Service Providers as a Driver of Customer Loyalty.” Journal of Supply Chain Management 45 (2): 75-93.

Wallenburg, C. M., A. M. Knemeyer, T. J. Goldsby, and D. L. Cahill. 2010. "Developing a Scale for Proactive Improvement within Logistics Outsourcing Relationship.” International Journal of Logistics Management 21 (1): 5-21.

Wong, W. P., K. L. Soh, and M. Goh. 2015. "Innovation and Productivity: Insights from Malaysia's Logistics Industry.” International Journal of Logistics: Research and Applications. doi:10.1080/13675567.2015.1077942.

Yeung, J. H. Y., W. Selen, C. Sum, and B. Huo. 2006. "Linking Financial Performance to Strategic Orientation and Operational Priorities: an Empirical Study of Third-Party Logistics Providers.” International Journal of Physical Distribution and Logistics Management 36 (3): 210-230.

Yin, R. K. 2013. Case Study Research: Design and Methods, SAGE Publications. 
Zhou, G., H. Min, C. Xu, and Z. Cao. 2008. "Evaluating the Comparative Efficiency of Chinese Third-Party Logistics Providers Using Data Envelopment Analysis.” International Journal of Physical Distribution and Logistics Management 38 (4): 262-279. 


\begin{tabular}{|c|c|c|c|c|c|c|}
\hline & & Average & $\begin{array}{l}\text { Standard } \\
\text { Deviation }\end{array}$ & $\begin{array}{c}\text { Coefficient } \\
\text { of } \\
\text { variation }\end{array}$ & Min & Max \\
\hline & \multicolumn{6}{|c|}{ Input [k€] } \\
\hline \multirow{4}{*}{$\begin{array}{c}\text { Net fixed } \\
\text { assets }\end{array}$} & 2009 & 10,571 & 20,366 & 1.93 & 39 & 140,207 \\
\hline & 2010 & 10,738 & 20,061 & 1.87 & 70 & 139,523 \\
\hline & 2011 & 9,707 & 19,488 & 2.01 & 69 & 144,295 \\
\hline & 2012 & 11,689 & 21,796 & 1.86 & 46 & 161,180 \\
\hline \multirow{4}{*}{$\begin{array}{c}\text { Salaries } \\
\text { and wages }\end{array}$} & 2009 & 7,713 & 10,391 & 1.35 & 114 & 45,045 \\
\hline & 2010 & 8,002 & 11,353 & 1.42 & 10 & 61,643 \\
\hline & 2011 & 8,361 & 11,334 & 1.36 & 10 & 56,404 \\
\hline & 2012 & 8,628 & 11,127 & 1.29 & 162 & 52,287 \\
\hline \multirow{4}{*}{$\begin{array}{c}\text { Operating } \\
\text { expenses }\end{array}$} & 2009 & 69,374 & 83,986 & 1.21 & 2,723 & 356,975 \\
\hline & 2010 & 80,203 & 104,598 & 1.30 & 4,073 & 497,723 \\
\hline & 2011 & 87,046 & 111,683 & 1.28 & 4,208 & 516,214 \\
\hline & 2012 & 86,921 & 107,506 & 1.24 & 1,246 & 509,288 \\
\hline \multirow{5}{*}{$\begin{array}{l}\text { Current } \\
\text { liabilities }\end{array}$} & 2009 & 30,423 & 32,237 & 1.06 & 1,576 & 140,692 \\
\hline & 2010 & 34,919 & 40,879 & 1.17 & 1,868 & 247,674 \\
\hline & 2011 & 37,361 & 40,297 & 1.08 & 2,258 & 227,745 \\
\hline & 2012 & 37,834 & 39,956 & 1.06 & 1,065 & 216,467 \\
\hline & \multicolumn{6}{|c|}{ Output [k€] } \\
\hline \multirow{4}{*}{ EBITDA } & 2009 & 3,270 & 4,055 & 1.24 & 10 & 17,203 \\
\hline & 2010 & 3,646 & 4,736 & 1.30 & 10 & 29,635 \\
\hline & 2011 & 3,635 & 4,331 & 1.19 & 10 & 20,683 \\
\hline & 2012 & 3,529 & 3,385 & 0.96 & 0 & 13,802 \\
\hline
\end{tabular}

Table 1. Summary of 3PL providers' measures $(n=71)$. 


\section{Industry Focus}

\begin{tabular}{ccccc}
\hline & & IF & IU & Total \\
\hline \multirow{3}{*}{ Size } & MS & 29 & 22 & $\mathbf{5 1}$ \\
\cline { 2 - 5 } & LS & 10 & 10 & $\mathbf{2 0}$ \\
\cline { 2 - 5 } & Total & $\mathbf{3 9}$ & $\mathbf{3 2}$ & $\mathbf{7 1}$
\end{tabular}

Note: IF = industry focussed; IU = industry unfocussed; MS = medium-size; LS = large-size.

Table 2. Sample characteristics. 


\begin{tabular}{lcccc|c}
\hline \multicolumn{1}{c}{ No. of companies $\mathbf{( \% )}$} & $\mathbf{2 0 0 9}$ & $\mathbf{2 0 1 0}$ & $\mathbf{2 0 1 1}$ & $\mathbf{2 0 1 2}$ & Average \\
\hline CCR efficiency score $=1$ & $6(8 \%)$ & $5(7 \%)$ & $10(14 \%)$ & $8(11 \%)$ & $7(10 \%)$ \\
\hline $0.8<=$ CCR efficiency & $4(6 \%)$ & $5(7 \%)$ & $3(4 \%)$ & $6(8 \%)$ & $5(7 \%)$ \\
score $<1$ & & & & & \\
\hline CCR efficiency score $<0.8$ & $61(86 \%)$ & $61(86 \%)$ & $58(82 \%)$ & $57(81 \%)$ & $59(83 \%)$ \\
\hline \multicolumn{1}{c}{ CCR efficiency score } & $\mathbf{2 0 0 9}$ & $\mathbf{2 0 1 0}$ & $\mathbf{2 0 1 1}$ & $\mathbf{2 0 1 2}$ & Average \\
\hline Average & 0.42 & 0.43 & 0.41 & 0.44 & 0.42 \\
\hline Median & 0.36 & 0.35 & 0.31 & 0.33 & 0.34 \\
\hline
\end{tabular}

Table 3. Summary of overall efficiency scores. 


\begin{tabular}{lcccc|c}
\hline \multicolumn{1}{c}{ No. of companies $\mathbf{( \% )}$} & $\mathbf{2 0 0 9}$ & $\mathbf{2 0 1 0}$ & $\mathbf{2 0 1 1}$ & $\mathbf{2 0 1 2}$ & Average \\
\hline BCC efficiency score $=1$ & $16(23 \%)$ & $17(24 \%)$ & $18(25 \%)$ & $19(27 \%)$ & $18(25 \%)$ \\
\hline $0.8<=$ BCC efficiency & $5(7 \%)$ & $11(15 \%)$ & $4(6 \%)$ & $6(8 \%)$ & $6(8 \%)$ \\
score $<1$ & & & & & \\
\hline BCC efficiency score $<0.8$ & $50(70 \%)$ & $43(61 \%)$ & $49(69 \%)$ & $46(65 \%)$ & $47(67 \%)$ \\
\hline \multicolumn{1}{c}{ BBC efficiency score } & $\mathbf{2 0 0 9}$ & $\mathbf{2 0 1 0}$ & $\mathbf{2 0 1 1}$ & $\mathbf{2 0 1 2}$ & Average \\
\hline Average & 0.55 & 0.60 & 0.53 & 0.57 & 0.56 \\
\hline Median & 0.54 & 0.60 & 0.47 & 0.55 & 0.54 \\
\hline
\end{tabular}

Table 4. Summary of technical efficiency scores. 


\begin{tabular}{lcccc|c}
\hline \multicolumn{1}{c}{ No. of companies (\%) } & $\mathbf{2 0 0 9}$ & $\mathbf{2 0 1 0}$ & $\mathbf{2 0 1 1}$ & $\mathbf{2 0 1 2}$ & Average \\
\hline Optimal Scale & $11(15.5 \%)$ & $8(11 \%)$ & $17(24 \%)$ & $13(18 \%)$ & $12(17 \%)$ \\
\hline Increasing Return to Scale & $18(25.5 \%)$ & $23(32.5 \%)$ & $21(30 \%)$ & $14(20 \%)$ & $19(27 \%)$ \\
\hline Decreasing Return to Scale & $42(59 \%)$ & $40(56.5 \%)$ & $33(46 \%)$ & $44(62 \%)$ & $40(56 \%)$ \\
\hline
\end{tabular}

Table 5. Summary of scale efficiency scores. 


\begin{tabular}{ccccc}
\hline No. $(\%)$ & $\mathbf{2 0 0 9 - 2 0 1 0}$ & $\mathbf{2 0 1 0 - 2 0 1 1}$ & $\mathbf{2 0 1 1 - 2 0 1 2}$ & Average \\
\hline PE ch. $>1$ & $39(55 \%)$ & $20(28 \%)$ & $34(48 \%)$ & $31(44 \%)$ \\
\hline PE ch. $<1$ & $21(30 \%)$ & $38(54 \%)$ & $25(35 \%)$ & $28(39 \%)$ \\
\hline PE ch. $=1$ & $11(15 \%)$ & $13(18 \%)$ & $12(17 \%)$ & $12(17 \%)$ \\
\hline
\end{tabular}

Table 6. Summary of Pure Efficiency Change (PE ch.) terms of MI. 


\begin{tabular}{lc|cc|c|cc}
\hline \multicolumn{1}{c}{\begin{tabular}{c} 
Average No. of \\
\multicolumn{1}{c}{ companies (\%) }
\end{tabular}} & Tot & MS & LS & Tot & MS & LS \\
\cline { 2 - 7 } $\begin{array}{l}\text { BCC efficiency score } \\
=1\end{array}$ & $\mathbf{1 3 ( 7 2 \% )}$ & $11(61 \%)$ & $2(11 \%)$ & $\mathbf{5 ( 2 8 \% )}$ & $4(22 \%)$ & $1(6 \%)$ \\
\hline \hline Optimal Scale & $\mathbf{9 ( 7 5 \% )}$ & $7(58 \%)$ & $2(17 \%)$ & $\mathbf{3 ( 2 5 \% )}$ & $3(25 \%)$ & $0(0 \%)$ \\
\hline $\begin{array}{l}\text { Increasing Return to } \\
\text { Scale }\end{array}$ & $\mathbf{1 2 ( 6 3 \% )}$ & $12(63 \%)$ & $0(0 \%)$ & $\mathbf{7 ( 3 7 \% )}$ & $7(37 \%)$ & $0(0 \%)$ \\
\hline $\begin{array}{l}\text { Decreasing Return to } \\
\text { Scale }\end{array}$ & $\mathbf{1 8 ( 4 5 \% )}$ & $10(25 \%)$ & $8(20 \%)$ & $\mathbf{2 2 ( 5 5 \% )}$ & $12(30 \%)$ & $10(25 \%)$ \\
\hline
\end{tabular}

Note: IF = Industry focussed; IU = Industry unfocussed; MS = medium-size; LS = large-size.

Table 7. Summary of DEA results distinguishing by 3PL providers characteristics. 


\begin{tabular}{lcccc}
\hline No. Of companies $(\boldsymbol{\%})$ & $\mathbf{2 0 0 9 - 2 0 1 0}$ & $\mathbf{2 0 1 0 - 2 0 1 1}$ & $\mathbf{2 0 1 1 - 2 0 1 2}$ & Average \\
\hline Innovative companies & $5(7 \%)$ & $10(14 \%)$ & $7(10 \%)$ & $7.3(10.3 \%)$ \\
\hline
\end{tabular}

Table 8: Summary of results about innovative DMUs. 


\begin{tabular}{|c|c|c|c|c|c|c|}
\hline \multirow{2}{*}{$\begin{array}{c}\text { Innovative companies } \\
\qquad(\%)\end{array}$} & \multicolumn{3}{|c|}{ IF } & \multicolumn{3}{|c|}{ IU } \\
\hline & Tot & MS & $\mathbf{L S}$ & Tot & MS & $\mathbf{L S}$ \\
\hline Average No. (\%) & $6(8.5 \%)$ & $5(7 \%)$ & $1(1.5 \%)$ & $1.3(2 \%)$ & $1.3(2 \%)$ & $0(0 \%)$ \\
\hline No. in 2009-2010 & 5 & 4 & 1 & $\mathbf{0}$ & 0 & 0 \\
\hline No. in $2010-2011$ & 7 & 6 & 1 & 3 & 3 & 0 \\
\hline No. in 2011-2012 & 6 & 6 & 0 & 1 & 1 & 0 \\
\hline
\end{tabular}

Note: IF = Industry focussed; IU = Industry unfocussed; MS = medium-size; LS = large-size.

Table 9. Summary of the results about innovative DMUs distinguishing by 3PL providers characteristics. 


\begin{tabular}{ccccc|cccc}
\hline No. & $\begin{array}{c}\text { Industry } \\
\text { Focus }\end{array}$ & Size & $\begin{array}{c}\text { Efficiency } \\
\text { degree }\end{array}$ & $\begin{array}{c}\text { Innovation } \\
\text { degree }\end{array}$ & $\begin{array}{c}\text { Net fixed } \\
\text { assets (\%) }\end{array}$ & $\begin{array}{c}\text { Salaries and } \\
\text { wages (\%) }\end{array}$ & $\begin{array}{c}\text { Operating } \\
\text { expenses (\%) }\end{array}$ & $\begin{array}{c}\text { Current } \\
\text { liabilities (\%) }\end{array}$ \\
\hline $\mathbf{1}$ & IF & MS & H & H & $7.8 \%$ & $0.4 \%$ & $50.7 \%$ & $41.1 \%$ \\
\hline $\mathbf{2 5}$ & IF & MS & H & H & $0.3 \%$ & $7.8 \%$ & $59.2 \%$ & $32.7 \%$ \\
\hline $\mathbf{2 8}$ & IF & MS & H & H & $38.9 \%$ & $7.3 \%$ & $38.5 \%$ & $15.3 \%$ \\
\hline $\mathbf{6 0}$ & IF & MS & H & H & $13.5 \%$ & $13.0 \%$ & $49.0 \%$ & $24.5 \%$ \\
\hline $\mathbf{6 6}$ & IF & MS & H & H & $9.8 \%$ & $5.2 \%$ & $63.9 \%$ & $21.1 \%$ \\
\hline $\mathbf{6 8}$ & IU & MS & H & H & $0.2 \%$ & $7.5 \%$ & $78.5 \%$ & $13.8 \%$ \\
\hline \hline $\mathbf{1 2}$ & IF & MS & H & L & $62.1 \%$ & $1.6 \%$ & $20.4 \%$ & $15.9 \%$ \\
\hline $\mathbf{1 4}$ & IU & LS & H & L & $2.2 \%$ & $7.3 \%$ & $62.2 \%$ & $28.3 \%$ \\
\hline $\mathbf{1 7}$ & IF & MS & H & L & $1.4 \%$ & $55.3 \%$ & $19.4 \%$ & $23.9 \%$ \\
\hline $\mathbf{2 3}$ & IF & MS & H & L & $1.8 \%$ & $6.3 \%$ & $68.2 \%$ & $23.7 \%$ \\
\hline $\mathbf{2 4}$ & IU & MS & H & L & $23.5 \%$ & $3.8 \%$ & $52.4 \%$ & $20.3 \%$ \\
\hline $\mathbf{3 0}$ & IF & LS & H & L & $3.1 \%$ & $4.8 \%$ & $72.7 \%$ & $19.4 \%$ \\
\hline $\mathbf{3 4}$ & IF & MS & H & L & $63.7 \%$ & $1.6 \%$ & $15.6 \%$ & $19.1 \%$ \\
\hline $\mathbf{3 7}$ & IF & LS & H & L & $4.7 \%$ & $9.0 \%$ & $52.9 \%$ & $33.4 \%$ \\
\hline $\mathbf{4 1}$ & IU & MS & H & L & $25.7 \%$ & $1.6 \%$ & $49.1 \%$ & $23.6 \%$ \\
\hline $\mathbf{4 4}$ & IU & MS & H & L & $1.0 \%$ & $2.2 \%$ & $68.3 \%$ & $28.5 \%$ \\
\hline $\mathbf{4 8}$ & IU & MS & H & L & $1.6 \%$ & $4.7 \%$ & $60.4 \%$ & $33.3 \%$ \\
\hline $\mathbf{5 9}$ & IF & MS & H & L & $2.0 \%$ & $0.9 \%$ & $71.3 \%$ & $25.8 \%$ \\
\hline $\mathbf{6 1}$ & IF & MS & H & L & $28.9 \%$ & $4.9 \%$ & $35.2 \%$ & $31.0 \%$ \\
\hline & & & & & & & & \\
\hline
\end{tabular}

Table 10. Input average composition of the best-in-class 3PL providers. 


\begin{tabular}{|c|c|c|c|c|c|c|c|}
\hline No. & Industry & Size & $\begin{array}{c}\text { Net fixed } \\
\text { assets (\%) }\end{array}$ & $\begin{array}{c}\text { Salaries and } \\
\text { wages }(\%)\end{array}$ & $\begin{array}{c}\text { Operating } \\
\text { expenses }(\%)\end{array}$ & $\begin{array}{c}\text { Current } \\
\text { liabilities }(\%)\end{array}$ & Interviewed \\
\hline $\begin{array}{c}\text { Company } \\
\text { A }\end{array}$ & $\begin{array}{c}\text { Food and large } \\
\text { retail }\end{array}$ & MS & $7.8 \%$ & $0.4 \%$ & $50.7 \%$ & $41.1 \%$ & $\begin{array}{c}\text { Business } \\
\text { Development } \\
\text { Manager }\end{array}$ \\
\hline $\begin{array}{c}\text { Company } \\
\text { B }\end{array}$ & $\begin{array}{c}\text { Aerospace, } \\
\text { energy, electronics } \\
\text { and defence }\end{array}$ & MS & $0.3 \%$ & $7.8 \%$ & $59.2 \%$ & $32.7 \%$ & $\begin{array}{c}\text { Business } \\
\text { Development } \\
\text { Manager }\end{array}$ \\
\hline
\end{tabular}

Table 11: Summary of case study characteristics. 


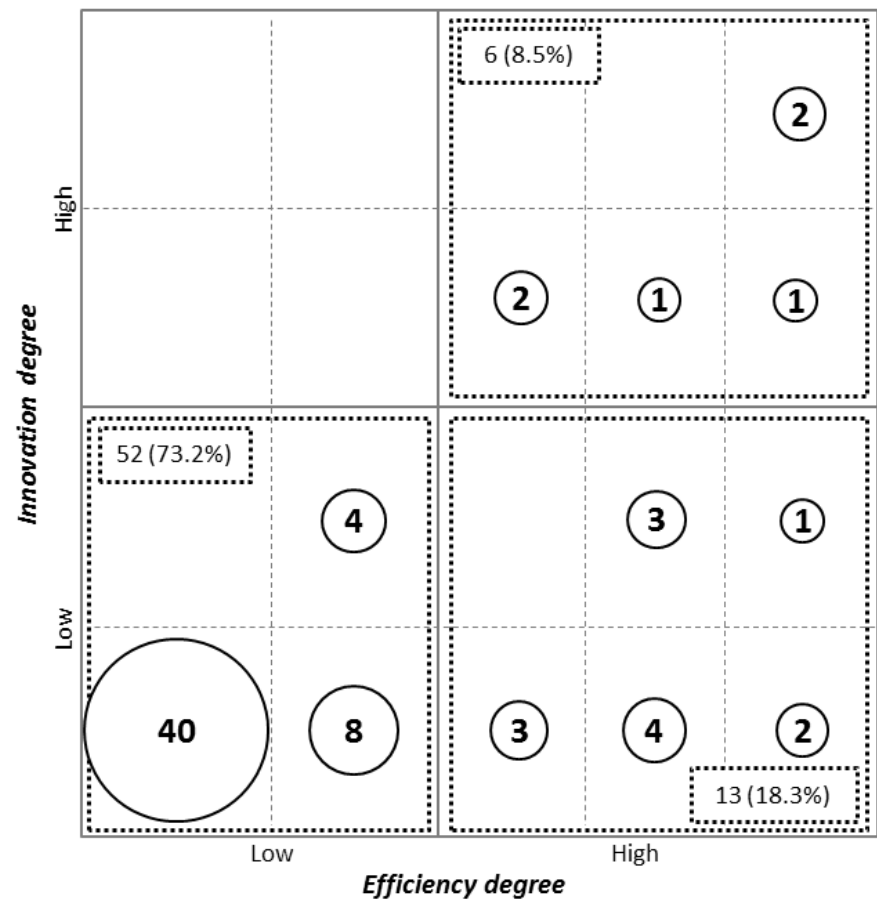

Figure 1. Efficiency and innovation cross-analysis. 